\title{
Tests on ferritic stainless steel simply supported and continuous SHS and RHS beams
}

Itsaso Arrayago, Esther Real, Enrique Mirambell

\section{SUMMARY}

Development of efficient design guidance for stainless steel structures (considering nonlinear behaviour, strain hardening and allowing for moment redistribution in indeterminate structures) is crucial for the widespread use of this corrosion-resistant material. This paper presents an experimental programme involving ferritic stainless steel simply supported and continuous beams (RHS and SHS) and the assessment of existing cross-sectional classifications and different plastic design methods available in the literature for indeterminate stainless steel structures, not currently allowed in stainless steel standards. The analysis indicated that some cross-sectional classification limits seem to be too optimistic for ferritic stainless steels and further research is needed in order to extend plastic design to these grades.

\section{KEYWORDS}

ferritic stainless steel, experimental program, simply supported beam tests, continuous beam tests, Continuous Strength Method, plastic design

\section{INTRODUCTION}

Current European design guidance on stainless steel in EN1993-1-4 [1] considers four cross-sectional classes depending on their local buckling susceptibility in a similar way to EN1993-1-1 [2] for carbon steel. A different resistance is assigned to each class. No plastic design is allowed for stainless steel elements in EN1993-1-4 [1] despite the fact that stainless steels are characterized by high ductility. That leads to overconservative 
predictions since strain hardening effects are not considered either. Considering that no experimental results on ferritic stainless steel continuous beams are available (as far as the authors are aware), an experimental programme involving simply supported and continuous beams was conducted and different design methods were assessed with these results to analyse the effect of the non-linear stress-strain relationship and strain hardening.

\section{EXPERIMENTAL PROGRAMME}

\subsection{Tensile tests and measured dimensions}

Five different rectangular and square hollow sections (RHS and SHS) were analysed as simply supported and continuous beam tests: S1-80x80x4, S2-60x60x3, S3-80x40x4, S4-120x80x3 and S5-70x50x2. All the specimens were produced in ferritic stainless steel grade EN1.4003.

Tensile tests were conducted on corner and flat coupons extracted from the specimens in accordance with ISO 6892-1 [3] provisions. Table 1 shows the weighted average tensile properties calculated considering the measured cross-sectional dimensions and tensile properties of flat and corner coupons, weighted according to the part of the total area that represents the whole cross-section, together with the measured dimensions of each element. In this table, $\mathrm{E}$ is the Young's modulus, $\sigma_{0.2}$ the $0.2 \%$ proof stress, $\sigma_{\mathrm{u}}$ the ultimate tensile stress of the material and $\varepsilon_{\mathrm{u}}$ the corresponding ultimate strain. Additionally, $\mathrm{H}$ represents the depth of the cross-section, $\mathrm{B}$ the width, $\mathrm{t}$ the thickness and $\mathrm{R}_{\mathrm{ext}}$ the external radius. The mean values and coefficients of variation $(\mathrm{COV})$ of the different parameters are presented for each cross-section. 
Table 1. Weighted tensile material properties and measured dimensions.

\begin{tabular}{cccccccccc}
\hline Section & & $\begin{array}{c}\mathrm{E} \\
{[\mathrm{GPa}]}\end{array}$ & $\begin{array}{c}\sigma_{0.2} \\
{[\mathrm{MPa}]}\end{array}$ & $\begin{array}{c}\sigma_{\mathrm{u}} \\
{[\mathrm{MPa}]}\end{array}$ & $\begin{array}{c}\varepsilon_{\mathrm{u}} \\
{[\%]}\end{array}$ & $\begin{array}{c}\mathrm{H} \\
{[\mathrm{mm}]}\end{array}$ & $\begin{array}{c}\mathrm{B} \\
{[\mathrm{mm}]}\end{array}$ & $\begin{array}{c}\mathrm{t} \\
{[\mathrm{mm}]}\end{array}$ & $\begin{array}{c}\mathrm{R}_{\text {ext }} \\
{[\mathrm{mm}]}\end{array}$ \\
\hline \multirow{2}{*}{ S1 } & Mean & 174 & 539 & 587 & 5.83 & 80.3 & 79.9 & 3.8 & 7.2 \\
& COV & 0.005 & 0.001 & 0.001 & 0.036 & 0.004 & 0.003 & 0.023 & 0.060 \\
S2 & Mean & 187 & 509 & 533 & 4.81 & 60.2 & 60.1 & 2.9 & 6.3 \\
& COV & 0.011 & 0.001 & 0.002 & 0.003 & 0.001 & 0.002 & 0.057 & 0.049 \\
S3 & Mean & 182 & 529 & 554 & 2.45 & 79.9 & 39.8 & 3.9 & 7.1 \\
& COV & 0.054 & 0.004 & 0.001 & 0.006 & 0.001 & 0.002 & 0.041 & 0.071 \\
S4 & Mean & 177 & 453 & 509 & 10.09 & 119.8 & 79.9 & 2.9 & 7.1 \\
& COV & 0.001 & 0.018 & 0.007 & 0.005 & 0.002 & 0.003 & 0.040 & 0.041 \\
S5 & Mean & 180 & 449 & 502 & 10.83 & 70.1 & 49.8 & 2.0 & 4.3 \\
& COV & 0.014 & 0.004 & 0.002 & 0.003 & 0.001 & 0.002 & 0.039 & 0.050 \\
\hline
\end{tabular}

\subsection{Simply supported beam tests}

Eight simply supported beams were tested under four-point bending loading conditions in order to determine the bending moment and rotation capacities of every cross-section, considering both major $(\mathrm{Mj})$ and minor $(\mathrm{Mi})$ bending axes for RHS. The beams were $1700 \mathrm{~mm}$ long with $1500 \mathrm{~mm}$ span lengths and were subjected to two line loads 480 mm apart applied at a distance of $510 \mathrm{~mm}$ from each support, as shown in Fig. 1.

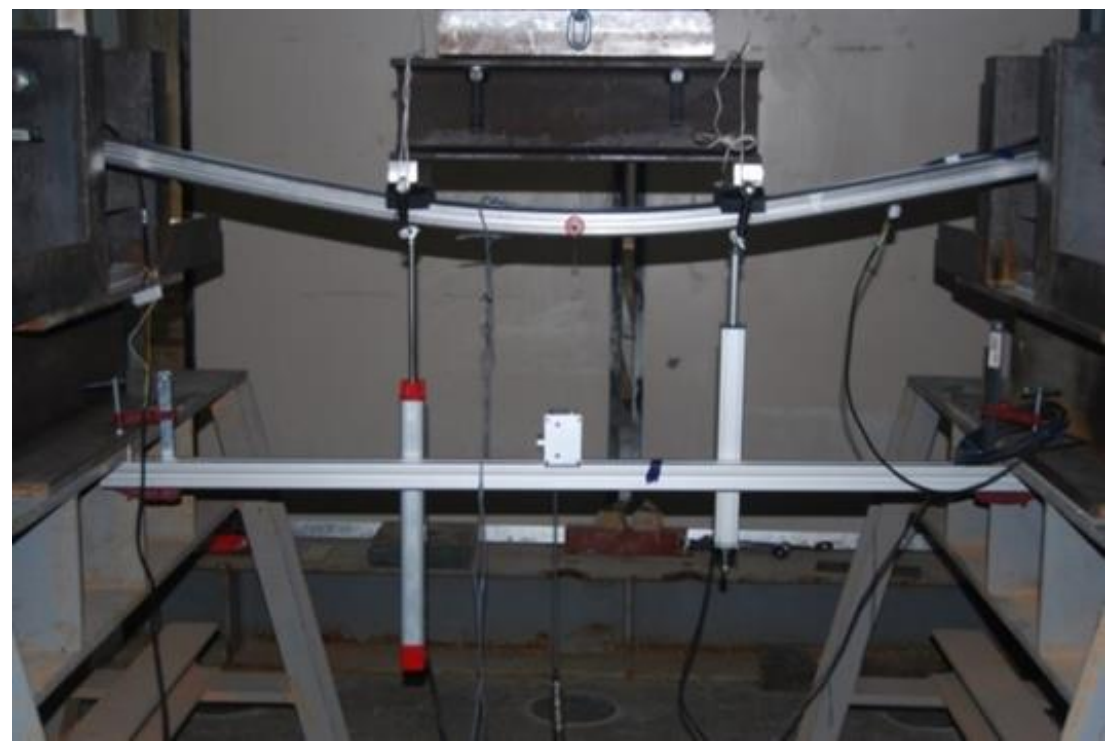

Figure 1. Test setup for four-point bending tests.

Loading and support sections were stiffened by inserting wooden blocks in order to prevent web crippling. The instrumentation of the beams consisted of load cells at both supports measuring reactions, displacement transducers measuring deflections at mid- 
span and loading sections, inclinometers recording end rotations at the support sections and strain gauges measuring the extreme tensile and compressive strains. The specimens were tested in a $1000 \mathrm{kN}$ MTS hydraulic machine under displacement control at a rate of $2 \mathrm{~mm} / \mathrm{min}$ and failed by local buckling of the compressed flange at loading sections. Table 2 presents the results of the simply supported beam tests: ultimate load $\mathrm{F}_{\mathrm{u}}$, corresponding mid-span deflection $\delta_{\mathrm{u}}$ and ultimate bending moment $\mathrm{M}_{\mathrm{u}}$. The comparison of the bending capacities against elastic $\mathrm{M}_{\mathrm{el}}$ and plastic $\mathrm{M}_{\mathrm{pl}}$ bending moment capacities is also included and, finally, the rotation capacity $\mathrm{R}=\kappa_{\mathrm{u}} / \kappa_{\mathrm{pl}}-1$ is provided for those beams showing a $\mathrm{M}_{\mathrm{u}} / \mathrm{M}_{\mathrm{pl}}$ ratio $>1$, where $\kappa_{\mathrm{u}}$ is the curvature at which the moment-curvature curve falls below $\mathrm{M}_{\mathrm{pl}}$ on the descending branch and $\kappa_{\mathrm{pl}}$ the elastic curvature corresponding to $\mathrm{M}_{\mathrm{pl}}$ on the ascending branch.

Table 2. Summary of experimental results for simply supported beams.

\begin{tabular}{ccccccc}
\hline Section & $\mathrm{F}_{\mathrm{u}}[\mathrm{kN}]$ & $\delta_{\mathrm{u}}[\mathrm{mm}]$ & $\mathrm{M}_{\mathrm{u}}[\mathrm{kNm}]$ & $\mathrm{M}_{\mathrm{u}} / \mathrm{M}_{\mathrm{el}}$ & $\mathrm{M}_{\mathrm{u}} / \mathrm{M}_{\mathrm{pl}}$ & $\mathrm{R}$ \\
\hline S1 & 66.1 & 42.4 & 16.9 & 1.18 & 0.96 & -- \\
S2 & 27.2 & 59.6 & 6.9 & 1.23 & 1.00 & 1.4 \\
S3-Mj & 43.2 & 63.8 & 11.0 & 1.36 & 1.02 & 1.8 \\
S3-Mi & 26.3 & 104.4 & 6.7 & 1.26 & 1.01 & 2.1 \\
S4-Mj & 64.1 & 16.3 & 16.3 & 1.03 & 0.84 & -- \\
S4-Mi & 48.6 & 22.5 & 12.4 & 0.97 & 0.83 & -- \\
S5-Mj & 19.2 & 48.0 & 4.9 & 1.26 & 1.03 & 1.9 \\
S5-Mi & 13.9 & 49.9 & 3.5 & 1.09 & 0.94 & -- \\
\hline
\end{tabular}

Table 2 shows that the only cross-section that did not reach the elastic bending capacity, and therefore experimentally classified as class 4, was S4-Mi. For sections S1, S4-Mj and S5-Mi, the ultimate bending capacities were between the elastic and plastic bending capacities, so they can be classified as class 3 . A minimum rotation capacity $R>3$ is adopted for guaranteeing moment redistribution in carbon steel cross-sections, and the same limit is usually required for stainless steels since no specific limit is provided, as noted in Theofanous et al. [4]. Therefore, the remaining cross-sections might be considered class 2 as they reach the plastic moment capacities, but their rotation capacity is $<3$. 


\subsection{Continuous beam tests}

Eight double-span continuous beam tests were also conducted in order to determine their redistribution capacity and to assess whether plastic design, which is not currently allowed for stainless steel structures, is applicable to ferritic stainless steel cold-formed beams. All specimens were $3200 \mathrm{~mm}$ long and were tested in a two-span structural configuration, with identical span lengths of $1500 \mathrm{~mm}$, subjected to two line loads applied at the mid-span section of each span, see Fig. 2.

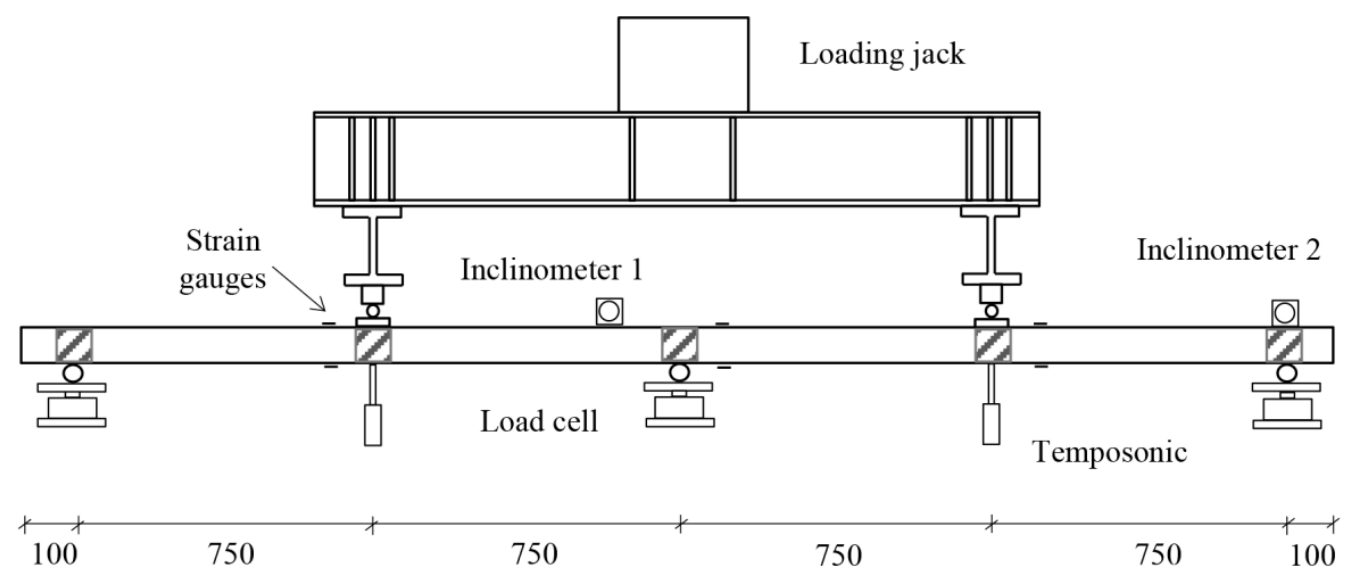

Figure 2. Test setup for continuous beam tests (dimensions in $\mathrm{mm}$ ).

Loading and support sections were also stiffened with wooden blocks in order to prevent web crippling and support reactions were measured by load cells in order to evaluate the reaction redistribution during the tests. Mid-span deflections were also recorded and rotations were measured at the outer support section of the right-hand span and at a distance of $250 \mathrm{~mm}$ from the internal support. Finally, extreme tensile and compressive strains were measured by several strain gauges at loading sections and the internal support. The specimens were tested under displacement control at a rate of $2 \mathrm{~mm} / \mathrm{min}$ and failed by local buckling of the compressed flange at the internal support and at the loading sections. The experimental results for continuous beam tests are summarized in Table 3, where ultimate load $\mathrm{F}_{\mathrm{u}}$ and the corresponding average mid-span deflection $\delta_{\mathrm{u}}$ are presented together with the measured reaction at the interior 
support $R_{\mathrm{u}}$. The rotations corresponding to $F_{u}$ at a distance of $250 \mathrm{~mm}$ from the internal support $\theta_{\mathrm{u}}{ }^{1}$ and at the outer support section $\theta_{\mathrm{u}}{ }^{2}$ are also given.

Table 3. Summary of experimental results for continuous beams.

\begin{tabular}{cccccc}
\hline Section & $\mathrm{F}_{\mathrm{u}}[\mathrm{kN}]$ & $\delta_{\mathrm{u}}[\mathrm{mm}]$ & $\mathrm{R}_{\mathrm{u}}[\mathrm{kN}]$ & $\theta_{\mathrm{u}}{ }^{1}[\mathrm{rad}]$ & $\theta_{\mathrm{u}}{ }^{2}[\mathrm{rad}]$ \\
\hline S1 & 119.5 & 24.6 & 79.8 & 0.047 & 0.025 \\
S2 & 51.7 & 29.1 & 34.0 & 0.053 & 0.038 \\
S3-Mj & 84.2 & 23.5 & 56.1 & 0.048 & 0.025 \\
S3-Mi & 52.4 & 47.4 & 34.6 & 0.068 & 0.047 \\
S4-Mj & 106.5 & 11.4 & 69.5 & 0.022 & 0.010 \\
S4-Mi & 87.4 & 16.7 & 58.7 & 0.029 & 0.012 \\
S5-Mj & 34.4 & 20.6 & 22.5 & 0.038 & 0.025 \\
S5-Mi & 26.7 & 27.8 & 17.6 & 0.055 & 0.033 \\
\hline
\end{tabular}

\section{ASSESSMENT OF EXISTING DESIGN METHODS}

\subsection{EN1993-1-4 and plastic design}

Expressions for determining the bending moment capacity of cross-sections according to EN1993-1-4 [1] depend on the section classification and can be summarized by Eq.(1), where $\mathrm{W}$ represents the plastic modulus $\mathrm{W}_{\mathrm{pl}}$ for class 1 or 2 cross-sections, the elastic modulus $\mathrm{W}_{\mathrm{el}}$ for class 3 and the effective modulus $\mathrm{W}_{\text {eff }}$ for class 4 .

$\mathrm{M}_{\mathrm{c}, \mathrm{Rk}}=\mathrm{W} \cdot \sigma_{0.2}$

Concerning continuous beams, EN1993-1-4 [1] considers that the collapse of the beam is reached upon the formation of the first plastic hinge at the central support, based on elastic calculations, without allowing any redistribution. This method usually results in excessively conservative predictions of the ultimate loads. Although plastic design is not currently allowed in EN1993-1-4 [1], the classical plastic design approach with a rigid-plastic material, as given in EN1993-1-1 [2], is also analysed in this paper in order to determine its accuracy and the possibility of recommending its inclusion in EN1993-1-4 [1] for stainless steel. 


\subsection{New design methods}

The development of accurate design methods or expressions that do not result in overconservative resistance predictions is doubly important when metallic materials with high strain hardening levels, such as stainless steel, are considered. Therefore, instead of considering discrete cross-sectional capacities, new design methods based on deformation capacity are of interest. The continuous strength method (CSM) is a new design method that considers the deformation capacity of a cross-section $\varepsilon_{\mathrm{csm}}$ in terms of its slenderness. The expressions used in the calculations presented in this paper can be found in detail in Afshan and Gardner [5], where the definition of the strain hardening modulus $\mathrm{E}_{\mathrm{sh}}$ for ferritic stainless steels provided by Bock et al. [6] has been considered.

In order to predict accurately the collapse loads of stocky stainless steel continuous elements, considering moment redistribution and strain hardening, Theofanous et al. [4] assessed the applicability of the new design method developed by Gardner et al. [7], the CSM for indeterminate structures. The method assigns the full CSM cross-sectional resistance to the critical plastic hinge and allows a degree of strain hardening for the rest of the hinges. The rotation demand of each hinge is calculated with Eq. (2), where $\theta_{\mathrm{i}}$ is the relative rotation derived from kinematics considerations for the collapse mechanism considered, $\mathrm{h}_{\mathrm{i}}$ the section depth at the location considered and $\left(\varepsilon_{\mathrm{csm}} / \varepsilon_{\mathrm{y}}\right)_{\mathrm{i}}$ the normalized strain ratio at the $\mathrm{i}^{\text {th }}$ hinge (with $\varepsilon_{\mathrm{y}}$ being the material yield strain). The critical hinge is that showing the greatest rotation capacity demand relative to the deformation capacity of the cross-section, and the rest of the rotation demands are calculated according to Eq.(3). The collapse load is then calculated using the virtual work principle as in conventional plastic design. Sufficient deformation capacity for moment redistribution to occur is guaranteed by ensuring a minimum value $\varepsilon_{\mathrm{csm}} / \varepsilon_{\mathrm{y}}=3.6$ for box sections according to Gardner et al. [7]. 
$\alpha_{i}=\frac{\theta_{i} \cdot h_{i}}{\left(\varepsilon_{\mathrm{csm}} / \varepsilon_{\mathrm{y}}\right)_{\mathrm{i}}}$

$\left(\frac{\varepsilon_{\mathrm{csm}}}{\varepsilon_{\mathrm{y}}}\right)_{\mathrm{i}}=\frac{\alpha_{\mathrm{i}}}{\alpha_{\mathrm{crit}}}\left(\frac{\varepsilon_{\mathrm{csm}}}{\varepsilon_{\mathrm{y}}}\right)_{\text {crit }} \leq\left(\frac{\varepsilon_{\mathrm{csm}}}{\varepsilon_{\mathrm{y}}}\right)_{\mathrm{i}, \mathrm{limit}}$

\subsection{Assessment of design methods and discussion}

An assessment of the design methods described for simply supported and continuous stainless steel beams is presented here. For simply supported beams, ultimate bending moment predictions have been calculated considering the cross-sectional classification currently provided in EN1993-1-4 [1] and the revised slenderness limits proposed by Gardner and Theofanous [8]. The assessment of the three methods is considered in Table 4 by presenting the cross-sectional class predicted by each classification and the predicted-to-experimental bending moment ratios. The $\varepsilon_{\mathrm{csm}} / \varepsilon_{\mathrm{y}}$ ratios are also presented in order to determine whether the CSM is applicable for indeterminate structures. Table 4 shows that all design approaches provide accurate predictions of the ultimate loads, especially CSM, although some unsafe results were found. The EN1993-1-4 [1] provisions also correctly predict experimental loads for the two classification limits considered.

Table 4. Assessment of existing design methods for simply supported beams.

\begin{tabular}{ccccccc}
\hline \multirow{2}{*}{ Section } & \multicolumn{2}{c}{ EN1993-1-4 [1] } & \multicolumn{2}{c}{ Revised limits [8] } & \multicolumn{2}{c}{ CSM } \\
\cline { 2 - 7 } & Class & $\mathrm{M}_{\mathrm{c}, \mathrm{Rk}} / \mathrm{M}_{\mathrm{u}}$ & Class & $\mathrm{M}_{\mathrm{c}, \mathrm{Rk}} / \mathrm{M}_{\mathrm{u}}$ & $\mathrm{M}_{\mathrm{csm}} / \mathrm{M}_{\mathrm{u}}$ & $\varepsilon_{\mathrm{csm}} / \varepsilon_{\mathrm{y}}$ \\
\hline S1 & 3 & 0.85 & 1 & 1.04 & 1.04 & 3.5 \\
$\mathrm{~S} 2$ & 2 & 1.00 & 1 & 1.00 & 1.00 & 5.5 \\
$\mathrm{~S} 3-\mathrm{Mj}$ & 1 & 0.98 & 1 & 0.98 & 1.01 & 4.7 \\
S3-Mi & 3 & 0.79 & 1 & 0.99 & 0.98 & 3.2 \\
S4-Mj & 4 & 0.95 & 3 & 0.97 & -- & 1.6 \\
S4-Mi & 4 & 0.81 & 4 & 0.84 & -- & 0.3 \\
S5-Mj & 4 & 0.79 & 1 & 0.97 & 0.93 & 1.9 \\
S5-Mi & 4 & 0.79 & 4 & 0.82 & -- & 0.5 \\
\hline Mean & & 0.87 & & 0.95 & 0.99 & -- \\
COV & 0.107 & & 0.081 & 0.041 & -- \\
\hline
\end{tabular}

Concerning continuous beam tests, the assessment of the different design methods presented above is considered in Table 5 by providing the predicted-to-experimental 
load ratios: $F_{h 1}$ represents the predicted ultimate load calculated with an elastic calculation when the first plastic hinge at the central support is formed, whereas $F_{u}$ is the collapse load allowing for plastic design where applicable. Both cross-sectional classification and CSM provisions have been considered. Note that for the continuous tests presented in this paper, the rotation capacity demand at the three plastic hinges is the same, so the full CSM resistance is assigned to all hinges, and the method is equivalent to considering classic plastic design with the bending moment capacity determined according to CSM.

Table 5. Assessment of existing design methods based on elastic analysis and allowing plastic design for continuous beams.

\begin{tabular}{ccccccccc}
\hline \multirow{2}{*}{ Section } & \multicolumn{3}{c}{ EN1993-1-4 [1] } & \multicolumn{3}{c}{ Revised limits [8] } & \multicolumn{2}{c}{ CSM } \\
\cline { 2 - 9 } & Class & $\mathrm{F}_{\mathrm{h} 1, \mathrm{EN}} / \mathrm{F}_{\mathrm{u}}$ & $\mathrm{F}_{\mathrm{u}, \mathrm{EN}} / \mathrm{F}_{\mathrm{u}}$ & Class & $\mathrm{F}_{\mathrm{h} 1, \text { revEN }} / \mathrm{F}_{\mathrm{u}}$ & $\mathrm{F}_{\mathrm{u}, \text { revEN }} / \mathrm{F}_{\mathrm{u}}$ & $\mathrm{F}_{\mathrm{h} 1, \mathrm{csm}} / \mathrm{F}_{\mathrm{u}}$ & $\mathrm{F}_{\mathrm{u}, \mathrm{csm}} / \mathrm{F}_{\mathrm{u}}$ \\
\hline $\mathrm{S} 1$ & 3 & 0.85 & 0.85 & 1 & 1.04 & 1.18 & 1.05 & 1.17 \\
$\mathrm{~S} 2$ & 2 & 0.95 & 0.95 & 1 & 0.95 & 1.08 & 0.97 & 1.08 \\
$\mathrm{~S} 3-\mathrm{Mj}$ & 1 & 0.92 & 1.04 & 1 & 0.92 & 1.04 & 0.95 & 1.06 \\
$\mathrm{~S} 3-\mathrm{Mi}$ & 3 & 0.72 & 0.72 & 1 & 0.90 & 1.03 & 0.91 & 1.02 \\
S4-Mj & 4 & 1.04 & 1.04 & 3 & 1.06 & 1.06 & -- & - \\
S4-Mi & 4 & 0.81 & 0.81 & 4 & 0.84 & 0.84 & -- & - \\
S5-Mj & 4 & 0.80 & 0.80 & 1 & 0.98 & 1.11 & 0.94 & 1.06 \\
S5-Mi & 4 & 0.74 & 0.74 & 4 & 0.77 & 0.77 & -- & -- \\
\hline Mean & & 0.85 & 0.87 & & 0.93 & 1.01 & 0.98 & 1.08 \\
COV. & 0.127 & 0.145 & & 0.105 & 0.136 & 0.064 & 0.053 \\
\hline
\end{tabular}

If elastic analysis is assumed $\left(\mathrm{F}_{\mathrm{h} 1}\right)$, the best ultimate predictions are obtained when CSM is used, as shown in Table 5, although one unsafe prediction was found for S1. However, both plastic design methods overestimate the experimental ultimate loads, indicating that current limits guaranteeing enough rotation capacity are too optimistic for ferritic stainless steels, which show considerably lower ductility than other stainless steel grades. Nevertheless, when more ductile stainless steel families, such as austenitic and lean duplex, are considered, accurate ultimate capacity estimations are obtained through plastic design methods, and CSM for indeterminate structures provides the best predictions of the collapse loads, as demonstrated in [4] and [7]. Therefore, some 
additional tests and parametric studies on stockier cross-sections are crucial for extending this study to ferritic stainless steel grades.

\section{RELIABILITY ANALYSIS}

In order to guarantee that approaches meet the reliability requirements in EN1993-1-4 [1] through the partial safety factors, it is necessary to consider the uncertainties derived from the variability of the material and geometrical properties as well as those associated with the theoretical prediction of the final capacity of the beam. Therefore, a statistical analysis was conducted according to the previsions given in EN1990 [9] and Tankova et al. [10], with the procedures and parameters reported in Afshan et al. [11]: the $\mathrm{V}_{\sigma 0.2}$ and $\mathrm{V}_{\text {geom }}$ parameters accounting for the variation of the material and geometric properties were taken as 0.030 and 0.050 respectively. Nominal resistances were calculated considering yield strengths equal to the experimental strength reduced by the over-strength factor (1.20 for ferritic stainless steels), as proposed in [11], since excessively conservative partial factors are obtained when the minimum specified $\sigma_{0.2}$ values are considered. Table 6 shows the calculated partial safety factors for the different approaches analysed in this paper for simply supported and continuous beams. However, for continuous beams, only the approaches derived from elastic calculations have been considered, since plastic design methods were found to provide unsafe capacity predictions.

Table 6. Summary of statistical analysis results for bending moment resistance.

\begin{tabular}{cccc}
\hline \multicolumn{5}{c}{ EN1993-1-4 [1] } & Revised limits [8] & CSM \\
\hline \multicolumn{4}{c}{ Simply supported beams } \\
$\gamma_{\mathrm{M} 0}$ & 1.02 & 1.04 & 1.07 \\
\hline \multicolumn{5}{c}{ Continuous beams } \\
\hline$\gamma_{\mathrm{M} 0}$ & 1.11 & 1.15 & 1.30 \\
\hline
\end{tabular}


Results in Table 6 suggest that for simply supported beams, the expression given in EN1993-1-4 [1] is conservative for ferritic stainless steels, regardless of the method considered, since the calculated partial factors are lower that the $\gamma_{\mathrm{M} 0}=1.10$ value given in EN1993-1-4 [1]. Regarding continuous beams, only the design approach in EN1993-1-4 [1] is conservative for the EN1993-1-4 [1] cross-sectional classification. When ultimate loads are determined considering revised limits and the CSM, higher $\gamma_{\mathrm{M} 0}$ values are obtained, so the adoption of the 1.10 value codified in EN1993-1-4 [1] would lead to unsafe results. Therefore, it is proposed that the current value of 1.10 is maintained for EN1993-1-4 [1] and that further research be conducted to validate alternative and plastic design methods.

\section{CONCLUSIONS}

This paper presents some tests on ferritic stainless steel simply supported and continuous beams and compares the experimental loads with those calculated according to different design approaches from standards and the literature. These comparisons highlighted that the EN1993-1-4 [1] provisions are safe and accurate for simply supported and continuous beams for the codified and revised class limits when plastic design is not considered. However, class 1 limits seem to be too optimistic and the applicability of plastic design methods to ferritic stainless steel structures needs to be analysed in depth in further research.

\section{ACKNOWLEDGEMENTS}

The authors would like to acknowledge the support of the Ministerio de Economía y Competitividad (Spain), under the Project BIA 2012-36373, for the experimental programme. The first author is also grateful to the Secretaria Generalitat d'Universitats i 
de Recerca del Departament d'Economia i Coneixement de la de Catalunya i del Fons Social Europeu for the FI-DGR 2014 grant.

\section{BIBLIOGRAPHY}

[1] EN 1993-1-4. Eurocode 3: design of steel structures - Part 1-4: general rules supplementary rules for stainless steels. Brussels: European Committee for Standardization (CEN), 2006.

[2] EN1993-1-1. Eurocode 3: design of steel structures - Part 1-1: general rules and rules for building. Brussels: European Committee for Standardization (CEN), 2005.

[3] EN ISO 6892-1. 2009. Metallic materials - Tensile testing - Part 1: Method of test at room temperature. Brussels: European Committee for Standardization (CEN); 2009.

[4] Theofanous, M., Saliba, N., Zhao, O. and Gardner, L.: Ultimate response of stainless steel continuous beams. Thin-Walled Structures 83 (2014), pp. 115-127.

[5] Afshan, S. and Gardner, L.: The continuous strength method for structural stainless steel design. Thin-Walled Structures 68 (2013), pp. 42-49.

[6] Bock, M., Gardner, L. and Real, E.: Material and local buckling response of ferritic stainless steel sections. Thin-Walled Structures 89 (2015), pp. 131-141.

[7] Gardner, L., Wang, F.C. and Liew, A.: Influence of strain hardening on the behaviour and design of steel structures. International Journal of Structural Stability and Dynamics 11(5) (2011), pp. 855-875.

[8] Gardner, L. and Theofanous, M.: Discrete and continuous treatment of local buckling in stainless steel elements. Journal of Constructional Steel Research 64 (2008), pp. 1207-1216. 
[9] EN 1990. Eurocode: basis of structural design. Brussels: European Committee for Standardization (CEN), 2002.

[10] Tankova, T., Simoes da Silva, L., Marques, L., Rebelo, C. and Taras, A.: Towards a standardized procedure for the safety assessment of stability design rules. Journal of Constructional Steel Research 103 (2014), pp. 290-302.

[11] Afshan, S., Francis, P., Baddoo, N.R. and Gardner, L.: Reliability analysis of structural stainless steel design provisions. Journal of Constructional Steel Research 114 (2015), pp. 293-304. 